\title{
IMPACT OF NANOFLUIDS ON EXTERNAL AND INTERNAL FLOW VIA NAVIER-STOKES AND CONVECTION- DIFFUSION EQUATIONS FOR PARALLEL PLATES WITH SLIP BOUNDARY CONDITIONS
}

\author{
R. C. S. M. Costa, \\ M. F. Curi \\ Centro Federal de Educação Tecnológica Celso \\ Suckow da Fonseca \\ Department of Mechanical Engineering \\ Rio de Janeiro, Itaguaí, Brazil \\ ricardocesar.smc@gmail.com \\ marcos.curi@cefet-rj.br \\ Received: Dec 07, 2020 \\ Revised: Jan 19, 2021 \\ Accepted: Feb 26, 2021
}

\section{ABSTRACT}

With the modernization and miniaturization of equipment and systems to increase the overall efficiency in smaller spaces, new cooling solutions need to be developed. Microfluidic in the last decades becomes a new way to get this. Nanofluids are used to attend this demand to optimize efficiency, with their improved thermohydraulic properties, especially different thermal conductivities. To determine the advantages of using a nanofluid for thermal exchange, the properties, parameters and modelling will be presented, and the differential equations necessary to obtain the results. In that sense, the basic theory of fluid mechanics and heat transfer, through the Navier-Stokes and Convection-Diffusion equation, is used in the two-dimensional steady-state formulation. Slip boundary conditions for the velocity field. Constant heat flux and constant temperature at the surface are used for the temperature field, initially without the flow's microscale effects. The external flow over a flat plate and internal flow between parallel plates will be studied. Considering a laminar flow, with the base fluid being water and engine oil, with various volumetric fractions of Single Wall and Multiple Wall Carbon Nanotubes. To determine the results and create the comparative graphs, the Wolfram Mathematica v.11 software will be used for solving the remaining partial differential equations.

Keywords: carbon nanotube, nanofluid, thermal conductivity, fluid mechanics, heat transfer, microscale flow

\section{NOMENCLATURE \\ $\mathrm{C}_{\mathrm{p}} \quad$ specific heat, J/kg.K \\ $\mathrm{C}_{\mathrm{f}} \quad$ friction coefficient \\ f dimensionless stream function \\ $\mathrm{k}$ thermal conductivity, W/m.K \\ $\mathrm{Nu}$ local Nusselt number \\ Pr Prandtl number of base fluid \\ $\mathrm{q}_{\mathrm{w}} \quad$ wall heat flux, $\mathrm{W} / \mathrm{m}^{2}$ \\ $\operatorname{Re}_{\mathrm{x}} \quad$ local Reynolds number \\ $\mathrm{T}$ local fluid temperature, $\mathrm{K}$ \\ $\mathrm{T}_{\infty} \quad$ free stream temperature, $\mathrm{K}$ \\ $\mathrm{u} \quad \mathrm{X}$-component of velocity, $\mathrm{m} / \mathrm{s}$ \\ $\mathrm{U}$ free stream velocity $\mathrm{m} / \mathrm{s}$ \\ $\mathrm{v} \quad \mathrm{y}$-component of velocity, $\mathrm{m} / \mathrm{s}$ \\ $\mathrm{x}$ distance along the plate, $\mathrm{m}$ \\ $\mathrm{y}$ distance normal to the plate, $\mathrm{m}$}

\section{Greek symbols}

$\begin{array}{ll}\alpha & \text { thermal diffusivity, } \mathrm{m}^{2} / \mathrm{s} \\ \beta & \text { slip parameter } \\ \phi & \text { volume fraction of ferrofluid } \\ \eta & \text { similarity variable } \\ \mu & \text { absolute viscosity, } \mathrm{M} . \mathrm{s} / \mathrm{m}^{2} \\ \nu & \text { kinematic viscosity, } \mathrm{m}^{2} / \mathrm{s} \\ \rho & \text { density, } \mathrm{kg} / \mathrm{m}^{3} \\ \rho C_{\mathrm{p}} & \text { heat capacity, } \mathrm{kg} / \mathrm{m}^{3}\end{array}$

$\theta \quad$ dimensionless temperatura

$\lambda$ dimensionless distance along the plate

$\Psi \quad$ stream function

\section{Subscripts \\ cnt carbon nanotube \\ f base fluid \\ nf nanofluid}

\section{INTRODUCTION}

Nanomaterials allow us to achieve superior properties to conventional materials and are already present in several sectors, such as medicine, engineering, information technology, etc. Among nanotechnology branches, nanofluids have proven to be a very effective way to meet the cooling problems of modern systems, which demand speed and reduced sizes. Nanofluids are denominated heat transfer fluids obtained from suspended particles of nanometric size (on the order of 1 to $100 \mathrm{~nm}$ ) in conventional base fluids, usually liquids (Yu et al., 2007), such as, for example, nanoparticles, nanotubes, nanofibers, nanowires, nanofilms (2D), nanocylinders (3D).

According to $\mathrm{Li}$ et al. (2009), any solid nanoparticle, which has high thermal conductivity, can be used in nanofluids as an additive. The most used 
and described in the literature are metallic particles, oxides and carbon nanotubes. As analyzed experimentally by several researchers, (Masuda et al., 1993); (Das et al., 2003); (Pak and Cho, 1998); (Xuan and Li, 2003); (Eastman et al., 2001); (Mintsa et al., 2009), increasing a small number of nanoparticles (usually less than $5 \%$ of the total volume) can improve the thermal conductivity of the fluid by up to $50 \%$.

Among the most studied nanomaterials, the Carbon Nanotubes (CNT), discovered by Iijima (1991), have stood out. Carbon nanotubes have high thermal conductivity and resistance, as well as rigidity and resilience (Zeng et al., 2006). In general, they are classified as Single-Walled Carbon Nanotubes (SWCNT) and Multi-Walled Carbon Nanotubes (MWCNT).

Due to the need for many resources and physical limitations, many studies are carried out to compare the results obtained experimentally with the numerical results, which has the ability to change settings more practically. Bayomy and Saghir (2017) used a $\gamma$ $\mathrm{A} 12 \mathrm{O} 3 /$ water nanofluid in an aluminum foam heatsink on a CPU. Using an experimental method, the results revealed that the highest local Nusselt number was reached with a concentration of $0.2 \%$ nanoparticles, obtaining the average Nusselt value $37 \%$ higher than water. The numerical result had a maximum relative error of 3\%. Akbaridoust et al. (2013) studied the flow of $\mathrm{CuO} /$ water nanofluid in helically coiled tubes finding, at first, very different values between experimental and numerical data. After adjusting to the dispersion model used, using FORTRAN, they reached an insignificant difference between the heat transfer coefficient and the pressure drop, which was improved over the base fluid.

Nanofluids have demonstrated innovation in several areas, such as improving the thermal efficiency of solar collectors. Akbaridoust et al. (2017) analyzed nanofluids of $\mathrm{Al} 2 \mathrm{O} 3 /$ water and obtained numerical models, together with experimental data, results of $7.54 \%$ increase in thermal efficiency with a concentration of $3 \%$ of the nanoparticles. Borode et al. (2019) used carbon-based nanoparticles with water as a base fluid, with a low concentration of about $0.3 \%$. They improved the collector efficiency of a flat plate, evacuated tube and parabolic trough up to $95,12 \%$, $93,43 \%$ and $74,7 \%$, respectively.

The analysis of the thermal conductivity of the nanofluid is fundamental to describe its efficiency in heat transfer. First developed by Maxwell (1873), it has already been adapted by several authors to get closer to experimental physical reality. The model used in this work is the one developed in Xue (2005).

Determined through the Mixture Theory, density and specific heat are equally important physical properties, such as viscosity, directly proportional to the increase in the volumetric fraction, which implies a much more viscous fluid with high concentrations of nanoparticles. The viscosity equation model will be the one presented by Brinkman (1952).
The case for two-dimensional external flow on a flat plate and internal flow between flat plates will be studied. Finally, the continuity, momentum, and energy equations will be applied, following the geometry's boundary conditions and its hypotheses. Considering a laminar flow, with the base fluid being water and engine oil, with various volumetric fractions of SWCNT and MWCNT. To solve this problem the NDSolve subroutine from Wolfram Mathematica software, using Finite Element Methods, (Wolfram, 2016), solved the coupled ODEs systems with absolute and relative error controls predetermined, was chosen. Then obtaining results and creating the comparative graphs showing any possible improvement.

\section{PROBLEM FORMULATION AND SOLUTION METHODOLOGY}

The external flow in a flat plate and the internal flow between parallel plates are the targets of this study, analyzing the nanofluids' thermo-hydraulic effects of carbon nanotubes in water and engine oil. For this, certain hypotheses and considerations were chosen for each case, obtaining their equations used in the numerical method.

\section{Thermophysical Properties of Nanofluids}

The thermophysical properties (density, specific heat and thermal conductivity) of the water: 997 $(\mathrm{kg} / \mathrm{m} 3), 4179(\mathrm{~J} / \mathrm{kg} . \mathrm{K})$ and $0.613(\mathrm{~W} / \mathrm{mK})$, of the SWCNT: $2600(\mathrm{~kg} / \mathrm{m} 3), 425(\mathrm{~J} / \mathrm{kg} . \mathrm{K})$ and 6600 (W/mK), and, finally, MWCNT: $3000(\mathrm{~kg} / \mathrm{m} 3), 796$ (J/kg.K) and $3000(\mathrm{~W} / \mathrm{mK})$. It is possible to calculate the thermophysical properties of the nanofluids formed as a function of the volumetric fractions $(\varphi)$ as:

$$
\begin{gathered}
\rho_{\mathrm{nf}}=(1-\phi) \rho_{\mathrm{f}}+\phi \rho_{\mathrm{cnt}} \\
\left(\rho \mathrm{C}_{\mathrm{p}}\right)_{\mathrm{nf}}=(1-\phi)\left(\rho \mathrm{C}_{\mathrm{p}}\right)_{\mathrm{f}}+\phi\left(\rho \mathrm{C}_{\mathrm{p}}\right)_{\mathrm{cnt}}
\end{gathered}
$$

Being $\rho_{\mathrm{nf}}$ the density of the nanofluid and $(\rho \mathrm{Cp})_{\mathrm{nf}}$ the thermal capacity of the nanofluid. The viscosity of the nanofluid $\left(\mu_{\mathrm{nf}}\right)$ will be obtained according to Brinkman (1952) and the thermal conductivity $\left(\mathrm{k}_{\mathrm{nf}}\right)$ according to Xue (2005):

$$
\begin{gathered}
\mu_{\mathrm{nf}}=\frac{\mu_{\mathrm{nf}}}{(1-\phi)^{2.5}} \\
\frac{\mathrm{k}_{\mathrm{nf}}}{\mathrm{k}_{\mathrm{f}}}=\frac{1-\phi+2 \phi \frac{\mathrm{k}_{\mathrm{cnt}}}{\mathrm{k}_{\mathrm{cnt}}-\mathrm{k}_{\mathrm{f}}} \ln \left[\frac{\mathrm{k}_{\mathrm{cnt}}+\mathrm{k}_{\mathrm{f}}}{2 \mathrm{k}_{\mathrm{f}}}\right]}{1-\phi+2 \phi \frac{\mathrm{k}_{\mathrm{f}}}{\mathrm{k}_{\mathrm{cnt}}-\mathrm{k}_{\mathrm{f}}} \ln \left[\frac{\mathrm{k}_{\mathrm{cnt}}+\mathrm{k}_{\mathrm{f}}}{2 \mathrm{k}_{\mathrm{f}}}\right]}
\end{gathered}
$$

Then, we have the expressions for thermal diffusion $\left(\alpha_{\mathrm{nf}}\right)$ and kinematic viscosity $\left(v_{\mathrm{nf}}\right)$ respectively:

$$
\alpha_{\mathrm{nf}}=\frac{\mathrm{k}_{\mathrm{nf}}}{\left(\rho \mathrm{C}_{\mathrm{p}}\right)_{\mathrm{nf}}}
$$




$$
v_{\mathrm{nf}}=\frac{\mu_{\mathrm{nf}}}{\rho_{\mathrm{nf}}}
$$

\section{External flow on a flat plate}

For this case of parallel external flow on a flat plate, simplifying hypotheses will be considered, namely: Newtonian fluid, laminar flow, steady state, without radiation, without viscous dissipation, incompressible fluid and two-dimensional flow. Two different cases will be tested to obtain the temperature variation and the Nusselt number, using constant temperature in the first case and prescribed surface heat flux in the second case.

The main equations, for both cases, to obtain the results are the mass conservation, moment conservation and energy conservation equations, after simplified, are given, respectively, by:

$$
\begin{gathered}
\frac{\partial u}{\partial x}+\frac{\partial v}{\partial y}=0 \\
u \frac{\partial u}{\partial x}+v \frac{\partial v}{\partial y}=v_{n f} \frac{\partial^{2} u}{\partial y^{2}} \\
u \frac{\partial T}{\partial x}+v \frac{\partial T}{\partial y}=\alpha_{n f} \frac{\partial^{2} T}{\partial y^{2}}
\end{gathered}
$$

With the following boundary conditions for the first case where the temperature is constant at the surface:

$$
\left\{\begin{array}{c}
\mathrm{v}=0, \mathrm{u}=\gamma \frac{\partial \mathrm{u}}{\partial \mathrm{y}}, \mathrm{T}=\mathrm{T}_{\mathrm{s}} ; \mathrm{y}=0 \\
\mathrm{u} \rightarrow \mathrm{U}_{\infty}, \mathrm{T} \rightarrow \mathrm{T}_{\infty} ; \mathrm{y} \rightarrow \infty
\end{array}\right.
$$

And for the second case where the heat flux is prescribed at the surface:

$$
\left\{\begin{array}{c}
\mathrm{v}=0, \mathrm{u}=\gamma \frac{\partial \mathrm{u}}{\partial \mathrm{y}}, \mathrm{q}_{\mathrm{w}}=-\mathrm{k} \frac{\partial \mathrm{T}}{\partial \mathrm{y}} ; \mathrm{y}=0 \\
\mathrm{u} \rightarrow \mathrm{U}_{\infty}, \mathrm{T} \rightarrow \mathrm{T}_{\infty} ; \mathrm{y} \rightarrow \infty
\end{array}\right.
$$

Where $\gamma$ is the slip parameter and $U \infty$ the free flow rate. To dimensionless the previous equations, you must consider changing the variable to speed, with a current function $\Psi(\mathrm{x}, \mathrm{y})$, defined as:

$$
\mathrm{u}=\frac{\partial \Psi}{\partial \mathrm{y}} ; \mathrm{v}=-\frac{\partial \Psi}{\partial \mathrm{x}}=0
$$

Applying to Eq. 7, the first admensionalized equation is obtained:

$$
\frac{\partial \Psi}{\partial \mathrm{x} \partial \mathrm{y}}+\left(-\frac{\partial \Psi}{\partial \mathrm{x} \partial \mathrm{y}}\right)=0
$$

For the other equations, the similarity solution method will be used, in which it can be attributed:

$$
\begin{aligned}
& \eta=\frac{y}{x} \sqrt{\operatorname{Re}_{x}} \\
& f(\eta)=\frac{\Psi}{v_{f} \sqrt{R e_{x}}}
\end{aligned}
$$

For constant temperature:

$$
\theta(\eta)=\frac{T-T_{\infty}}{T_{s}-T_{\infty}}
$$

For constant temperature:

$$
\theta(\eta)=\frac{T-T_{\infty}}{q_{w} x / k_{f}} \sqrt{\operatorname{Re}_{x}}
$$

Where $\eta$ is the similarity variable, having as a dependent variable. $\mathrm{Re}_{\mathrm{x}}=\mathrm{U}_{\infty} \mathrm{x} / \mathrm{v}_{\mathrm{f}}$, which represents the local Reynolds number, based on the free flow velocity and the kinematic viscosity of the base fluid, Ts is the surface temperature and $\mathrm{q}_{\mathrm{w}}$ is the heat flux at the surface. Equation 16 will be used for the first case and the Eq. 17 for the second.

Therefore, Eq.13, Eq.14 and Eq.15 can now be replaced in Eq.8 and Eq.9, as well as in the boundary conditions described in Eq.10, obtaining for both cases:

$$
\frac{1}{(1-\phi)^{2.5}\left(1-\phi+\frac{\phi \rho_{\mathrm{cnt}}}{\rho_{\mathrm{f}}}\right)} \mathrm{f}^{\prime \prime \prime}(\eta)+\frac{1}{2} \mathrm{f}(\eta) \mathrm{f}^{\prime \prime}(\eta)=0
$$

For constant temperature:

$$
\frac{1}{\operatorname{Pr}} \frac{k_{n f} / k_{f}}{\left[1-\phi+\frac{\phi\left(\rho C_{p}\right)_{c n t}}{\left(\rho C_{p}\right)_{f}}\right.} \theta^{\prime \prime}(\eta)+\frac{1}{2}\left(f(\eta) \theta^{\prime}(\eta)\right)=0
$$

$$
\left\{\begin{array}{c}
f(\eta)=0, f^{\prime}(\eta)=\frac{\beta}{(1-\phi)^{2.5}}, \theta(\eta)=1 ; \eta=0 \\
f^{\prime}(\eta) \rightarrow 1, \theta(\eta) \rightarrow 0 ; \eta \rightarrow \infty
\end{array}\right.
$$

For constant temperature:

$$
\begin{aligned}
& \frac{1}{\operatorname{Pr}} \frac{\mathrm{k}_{\mathrm{nf}} / \mathrm{k}_{\mathrm{f}}}{\phi 1-\phi+\frac{\phi\left(\rho \mathrm{C}_{\mathrm{p}}\right)_{\mathrm{cnt}}}{\left(\rho \mathrm{C}_{\mathrm{p}}\right)_{\mathrm{f}}}} \theta^{\prime \prime}(\eta)+\frac{1}{2}\left(\mathrm{f}(\eta) \theta^{\prime}(\eta)-\right. \\
& \left.\mathrm{f}^{\prime}(\eta) \theta(\eta)\right)=0 \\
& \left\{\begin{aligned}
f(\eta)=0, & f^{\prime}(\eta)=\frac{\beta}{(1-\phi)^{2.5}}, \theta^{\prime}(\eta)=-\frac{k_{f}}{k_{n f}} ; \eta=0 \\
f^{\prime}(\eta) & \rightarrow 1, \theta(\eta) \rightarrow 0 ; \eta \rightarrow \infty
\end{aligned}\right.
\end{aligned}
$$

Where $\operatorname{Pr}=\left(\mu \mathrm{C}_{\mathrm{p}}\right) / \mathrm{k}_{\mathrm{f}}$ the Prandtl number of the base fluid, $\beta=\mathrm{U}_{\infty} \gamma / v_{\mathrm{f}}$ is the dimensionless slip parameter. Two dimensionless parameters are needed to make comparisons of thermohydraulic effects, they are: friction coefficient $\left(\mathrm{C}_{\mathrm{f}}=\tau_{\mathrm{W}} / \rho_{\mathrm{f}} \mathrm{U}_{\infty}{ }^{2}\right)$, used to determine the viscous drag on the surface and local Nusselt Number $\left(\mathrm{Nu}_{\mathrm{x}}=\mathrm{xq}_{\mathrm{w}} / \mathrm{k}_{\mathrm{nf}}\left(\mathrm{T}_{\mathrm{s}}-\mathrm{T}_{\infty}\right)\right)$. With these definitions, we can apply the similarity variables obtained previously, thus getting the final parameters 
of Coefficient of Friction and Nusselt Number, given by:

$$
\begin{gathered}
\operatorname{Re}_{\mathrm{x}}^{1 / 2} C_{\mathrm{f}}=\frac{1}{(1-\phi)^{2.5}} \mathrm{f}^{\prime \prime}(0) \\
\operatorname{Re}_{\mathrm{x}}^{-1 / 2} \mathrm{Nu}=-\frac{\mathrm{k}_{\mathrm{nf}}}{\mathrm{k}_{\mathrm{f}}} \theta^{\prime}(0)-\text { For constant temperature } \\
\operatorname{Re}_{\mathrm{x}}^{-1 / 2} \mathrm{Nu}=\frac{\mathrm{k}_{\mathrm{nf}}}{\mathrm{k}_{\mathrm{f}}} \frac{1}{\theta(0)}-\text { For prescribed heat flux }
\end{gathered}
$$

These equations will be applied to the numerical study and discussed in the results, together with the dimensionless temperature and velocity parameters. Eq. 24 and Eq. 25 for the first and second case, respectively.

\section{Internal flow between parallel plates}

The case of internal flow between parallel plates will be considered: Newtonian fluid, laminar flow, steady state, without radiation, without viscous dissipation, incompressible fluid and two-dimensional flow. The boundary condition of constant temperature will be used. As already studied in the literature, the friction coefficient is constant for this simplified case.

The main equations to obtain the results are moment conservation and energy conservation equations, after simplified, are given, respectively, by:

$$
\begin{gathered}
\mu_{n f} \frac{\partial^{2} u}{\partial y^{2}}=\frac{\partial p}{\partial x} \\
u \frac{\partial T}{\partial x}=\alpha_{n f} \frac{\partial^{2} T}{\partial y^{2}}
\end{gathered}
$$

With the following boundary conditions:

$$
\left\{\begin{array}{c}
u=U_{\infty}, T=T_{i}, ; \quad x=0 \\
\frac{\partial u}{\partial y}=0, \frac{\partial T}{\partial y}=0 ; \quad y=0 \\
u=-\gamma \frac{\partial u}{\partial y}, T=T_{s} ; y=1
\end{array}\right.
$$

For the admensionalization, the following parameters will be used:

$$
\begin{gathered}
\eta=\frac{y}{L} \\
f(\eta)=-u \frac{\mu_{f}}{L^{2}\left(\frac{\partial p}{\partial x}\right)} \\
\lambda=\frac{x}{C_{1}} \\
\theta(\lambda, \eta)=\frac{T-T_{s}}{T_{i}-T_{s}}
\end{gathered}
$$

When $\mathrm{C}_{1}=\mathrm{L}^{2} \mathrm{u}_{\mathrm{m}} / \mathrm{v}_{\mathrm{f}}$. Replacing Eq. 29, Eq. 30, Eq. 31 and Eq. 32 in Eq. 26, Eq. 27 and Eq. 28 is obtained:

$$
\begin{gathered}
\frac{\partial^{2} \mathrm{f}}{\partial \eta^{2}}=-(1-\phi)^{2.5} \\
\frac{1}{\operatorname{Pr}} \frac{\mathrm{k}_{\mathrm{nf}} / \mathrm{k}_{\mathrm{f}}}{\left[1-\phi+\frac{\phi\left(\rho \mathrm{C}_{\mathrm{p}}\right)_{\mathrm{cnt}}}{\left(\rho \mathrm{C}_{\mathrm{p}}\right)_{\mathrm{f}}}\right.} \frac{\partial^{2} \theta}{\partial \eta^{2}}=\mathrm{f}(\eta) \frac{\partial \theta}{\partial \lambda}
\end{gathered}
$$

With the following dimensionless boundary conditions:

$$
\left\{\begin{array}{c}
\theta(0, \eta)=1, \lambda=0, \frac{\partial \mathrm{f}}{\partial \eta}=0, \frac{\partial \theta}{\partial \eta}=0 ; \eta=0 \\
f(\eta)=-\frac{\beta}{\operatorname{Re}} \frac{\partial \mathrm{f}}{\partial \eta}, \theta(\lambda, 1)=0 ; \eta=1
\end{array}\right.
$$

For local Nusselt number, two properties need to be defined, average speed and average temperature, given by the equations:

$$
\begin{gathered}
\mathrm{f}_{\mathrm{m}}=\int_{0}^{1} \mathrm{f}(\eta) \partial(\eta) \\
\theta_{\mathrm{m}}=\int_{0}^{1} \frac{\mathrm{f}(\eta)}{\mathrm{fm}} \theta(\lambda, \eta) \partial(\eta)\left(\frac{1}{\left.\int_{0}^{1 \frac{1(\eta)}{\mathrm{fm}} \partial(\eta)}\right)}\right.
\end{gathered}
$$

For local Nusselt number, two properties need to be defined, average speed and average temperature, given by the equations:

$$
\mathrm{Nu}_{\mathrm{x}}(\lambda)=-\frac{\mathrm{k}_{\mathrm{nf}}}{\mathrm{k}_{\mathrm{f}}} \frac{1}{\theta \mathrm{m}} \frac{\partial}{\partial \eta}[\theta(\lambda, 1)]
$$

\section{RESULTS AND DISCUSSIONS}

Through the Wolfram Mathematica 11 software, the analyzes related to the velocity, temperature, friction coefficient and Nusselt number of the nanofluids were calculated and presented next.

\section{External flow on a flat plate}

The results in orange lines are the SWCNT, and black dashed lines are the MWCNT. Each simulation used as base fluid Water and Engine Oil, with $\mathrm{Pr}=6.2$ and $\operatorname{Pr}=6450$, respectively. The first analyses, seen in Fig. 1 and Fig. 2, are the effects of the variation of the volume fraction of the nanotubes $\varphi$ cause to the velocity and the friction coefficient for different values of $\beta$.
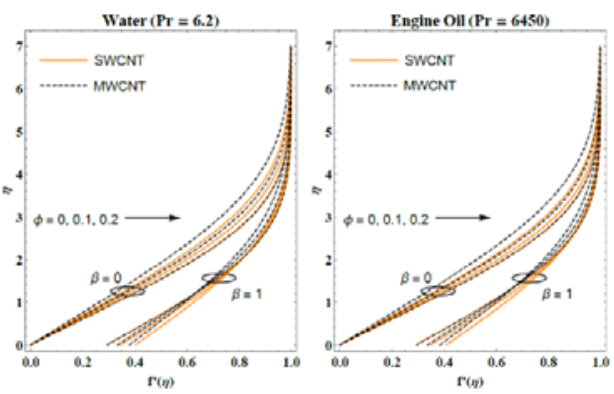
Figure 1. Variation of dimensionless velocity for water and engine oil with SWCNT and MWCNT.

As shown in Figure 1, it can be seen that in the absence of the slip speed $(\beta=0)$, the dimensionless speed on the surface is equal to zero, increasing with the increase in the slip speed. The increase in the volumetric fraction of nanotubes is directly proportional to the dimensionless velocity. With the increase of these two parameters, it gets closer to the U $\infty$. shows that the increase in the concentration of carbon nanotubes increases the nanofluid's friction. As the slip velocity increases, the friction decreases, drawing attention to a smaller difference between single-walled nanotubes and multi- walled ones with this increase. The results for the dimensionless temperature are shown in Fig. 3 and Fig. 4.

The increase in the thermal conductivity of the $\mathrm{k}_{\mathrm{nf}}$ nanofluid is directly linked to the speed with which thermal equilibrium is achieved, as shown in the graphics. Despite this, there is no perceptive difference for the first case (with constant temperature) and a small difference for the second case (with prescribed heat flux) compared to single-walled and multi-walled nanotubes, even though they have very different thermal conductivity. Finally, the results for the variation of Nusselt number are shown in Fig. 5 and Fig. 6.

As in the case of temperature, the increase in thermal conductivity causes the Nusselt number to increase. We can observe this with the addition of Carbon Nanotubes (mainly single-walled), which increases the thermal conductivity, showing that small variations in concentration can make the Nusselt number vary a lot for both cases. As the slip increases, the Nusselt number also increases, even with the pure base fluid. This is because it increases the speed of the fluid, causing the convective coefficient to become higher.

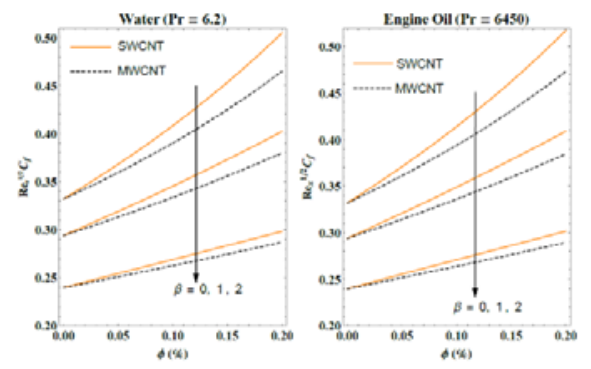

Figure 2. Variation of friction coefficient for water and engine oil with SWCNT and MWCNT.
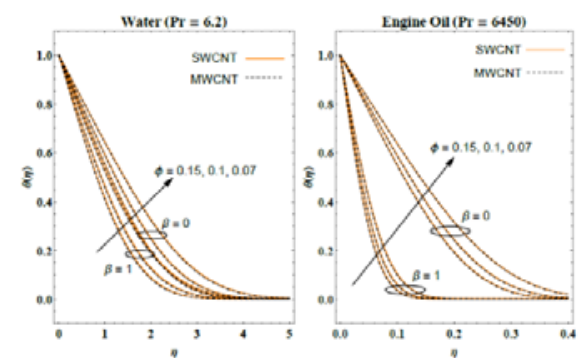

Figure 3. Variation of dimensionless temperature for water and engine oil with SWCNT and MWCNT for constant temperature.
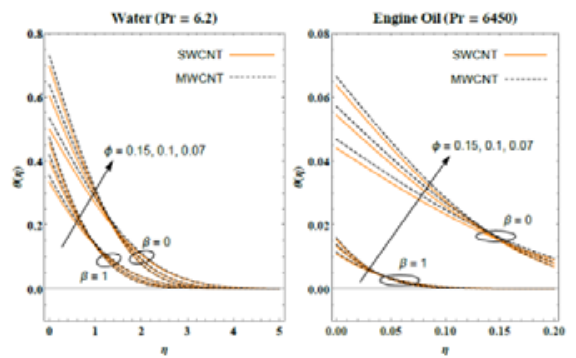

Figure 4. Variation of dimensionless temperature for water and engine oil with SWCNT and MWCNT for prescribed heat flux.

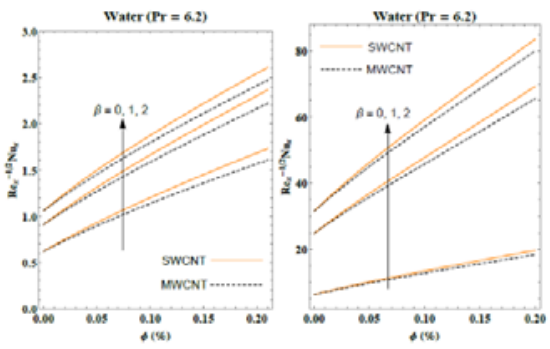

Figure 5. Variation of Nusselt number for water and engine oil with SWCNT and MWCNT for constant temperature.

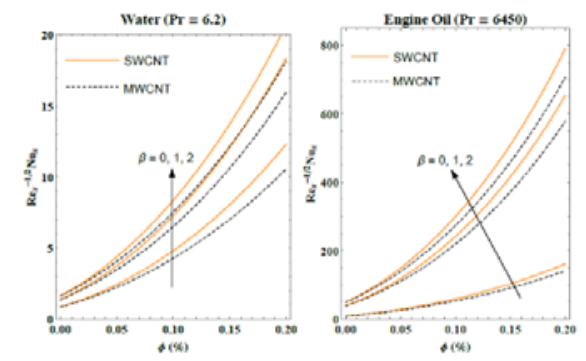

Figure 6. Variation of Nusselt number for water with SWCNT and MWCNT for prescribed heat flux.

\section{Internal flow between parallel plates}

As in the external flow case, the orange lines are the SWCNT results, and black dashed lines are the MWCNT results. All simulations used as base fluid Water and engine oil, with $\operatorname{Pr}=6.2$ and $\operatorname{Pr}=6450$, respectively. The friction coefficient is constant for this simplified case. 
Figure 7 shows the effects of the variation of the volume fraction of the nanotubes $\varphi$ cause to the velocity. In this case, when $\beta=0$, the dimensionless speed on the surface is no more equal to zero, and it grows to higher velocity values. The increase in the volumetric fraction of nanotubes is directly proportional to the dimensionless velocity. The values for water and oil are similar to this case.

The dimensionless temperature results can be seen in Fig. 8, for water, and Fig. 9, for engine oil, for values of $\lambda=1$ and $\lambda=2000$, for water and oil, respectively. As shown in the graphs, thermal equilibrium happens faster, the higher the $\beta$ value and the concentration of the nanoparticles, demonstrating, in this case, that there is an impact of the value of the nanofluid's thermal conductivity, which becomes greater with the highest concentration. It is seen that the engine oil reaches equilibrium before the water under the same conditions, as well as in nanofluids with SWCNT, which have higher thermal conductivity values than MWCNT.

The dimensionless temperature results can be seen in Fig. 8, for water, and Fig. 9, for engine oil, for values of $\lambda=1$ and $\lambda=2000$, for water and oil, respectively. As shown in the graphs, thermal equilibrium happens faster, the higher the $\beta$ value and the concentration of the nanoparticles, demonstrating, in this case, that there is an impact of the value of the nanofluid's thermal conductivity, which becomes greater with the highest concentration. It is seen that the engine oil reaches equilibrium before the water under the same conditions, as well as in nanofluids with SWCNT, which have higher thermal conductivity values than MWCNT.
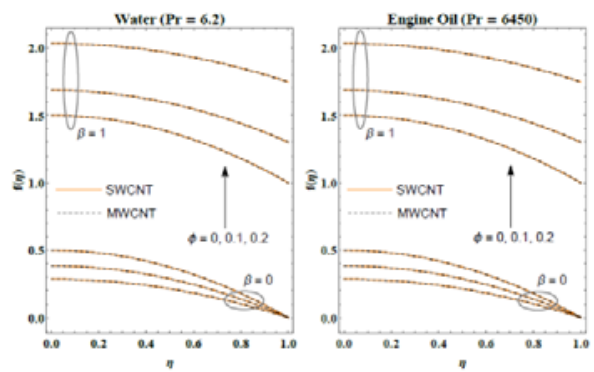

Figure 7. Variation of dimensionless velocity for water and engine oil with SWCNT and MWCNT.
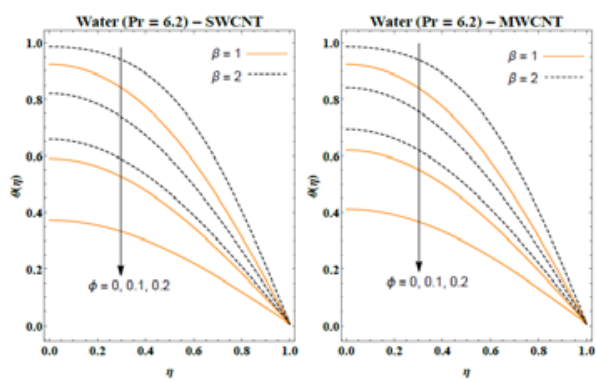

Figure 8. Variation of dimensionless temperature for water with SWCNT and MWCNT.

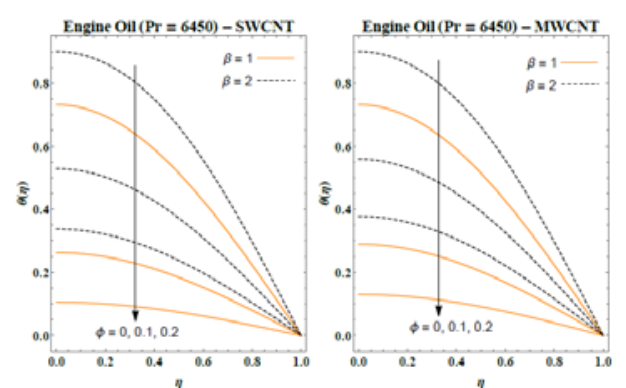

Figure 9. Variation of dimensionless temperature for engine oil with SWCNT and MWCNT.

In Figure 10, the flow analyzed is in the fully developed region. For this, a $\lambda=1000$ was considered for both cases of base fluids. the results show the variation in the volume fraction of the nanoparticles is directly proportional to the variation in the Nusselt number, as well as the slip velocity, as seen in the case of external flow, due to increases in thermal conductivity and the convective coefficient.
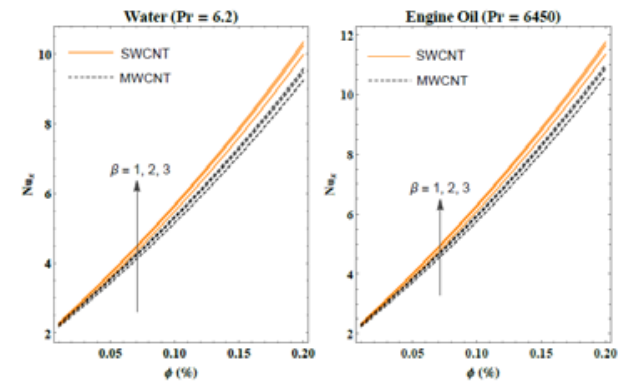

Figure 10. Variation of Nusselt number for water and engine oil with SWCNT and MWCNT.

\section{CONCLUSIONS}

We studied the temperature and velocity field, from the dimensionless momentum and energy equations for external convection over a flat a plate and internal convection between parallel plates. Also, the friction coefficient and Nusselt number, were observed, varying $\varphi$ and $\beta$. Through the results obtained numerically by the Wolfram Mathematica v.11 software for both cases (internal and external flow) it was possible to note the advantages of using a nanofluid for systems that demand increasingly innovative solutions compared to common base fluids. In addition to being more advantageous for pumping and storage systems than fluids added with mili or microparticles. This study can be applied, following the boundary conditions and appropriate hypotheses, for any geometry, in external or internal flows.

\section{REFERENCES}

Akbaridoust, F., Rakhsha, M., Abbassi, A. and Avval, M.S., 2013. "Experimental and numerical investigation of nanofluid heat transfer in helically coiled tubes at constant wall temperature using 
dispersion model". International Journal of Heat and Mass Transfer, Vol. 58, pp. 480-491.

Akbaridoust, F., Rakhsha, M., Abbassi, A. and Avval, M.S., 2017. "Numerical simulation of thermal efficiency of an innovative al2o3 nanofluid solar thermal collector influence of nanoparticles concentration". Thermal Science, Vol. 21, No. 6B, pp. 2769-2779.

Bayomy, A.M. and Saghir, M.Z., 2017. "Experimental study of using c-al2o3-water nanofluid flow through aluminum foam heat sink: Comparison with numerical approach". International Journal of Heat and Mass Transfer, Vol. 107, pp. 181-203.

Borode, A., Ahmed, N. and Olubambi, P., 2019. "A review of solar collectors using carbon-based nanofluids". Journal of Cleaner Production, Vol. 241.

Brinkman, H.C., 1952. "The viscosity of concentrated suspensions and solutions".

Das, S.K., Putra, N., Thiesen, P. and Roetzel, W., 2003. "Temperature dependence of thermal conductivity enhancement for nanofluids". Journal of Heat Transfer, Vol. 125, No. 4, pp. 567-574.

Eastman, J.A., Choi, S.U.S., Yu, W. and Thompson, L.J., 2001. "Anomalously increased effective thermal conductivities of ethylene glycolbased nanofluids containing copper nanoparticles". Powder Technology.

Iijima, S., 1991. "Helical microtubules of graphitic carbon". Nature, Vol. 354, No. 6348, pp. 5658.

Li, Y., Zhou, J., Tung, S., Schneider, E. and Xi, S., 2009. "A review on development of nanofluid preparation and characterization". Powder Technology, Vol. 196, No. 2, pp. 89-101.

Masuda, H., Ebata, A. and Hishinuma, K.T.N., 1993. "Alternative of thermal conductivity and viscosity of liquid by dispersing ultra-fine particles (dispersion of a -al2o3, sio2 and tio2 ultra-fine particles". Netsu Bussei, Vol. 7, No. 3, pp. 227-233.

Maxwell, J.C., 1873. "A treatise on electricity and magnetism".

Mintsa, H.A., Roy, G., Nguyen, C.T. and Doucet, D., 2009. "New temperature dependent thermal conductivity data for water-based nanofluids". Int J Therm Sci, Vol. 48, No. 2, pp. 363-371.

Pak, B.C. and Cho, Y.I., 1998. "Hydrodynamic and heat transfer study of dispersed fluids with submicron metallic oxide particles". Exp Heat Transf, Vol. 11, No. 2, pp. 151-170.

Wolfram, S., 2016. "Wolfram mathematica 11". In Wolfram Research Inc. Champaign, IL.

Xuan, Y. and Li, Q., 2003. "Investigation on convective heat transfer and flow features of nanofluids". Journal of Heat Transfer, Vol. 125, No. 1, pp. 151-155.

Xue, Q., 2005. "Model for thermal conductivity of carbon nanotubebased composites".

Yu, W., France, D.M., Choi, S.U.S. and Routbort, J.L., 2007. "Review and assessment of nanofluid technology for transportation and other applications".

Zeng, Q., Li, Z. and Zhou, Y., 2006. "Syntesis and application of carbon nanotubes". Journal of Natural Gas Chemistry, Vol. 15, No. 3, pp. 235-246. 